\title{
Using Acute-phase Reactants to Inform the Development of Instruments for the Updated Psoriatic Arthritis Core Outcome Measurement Set
}

\author{
Musaab Elmamoun, Ying Ying Leung, Denis O’Sullivan, Ingrid Steinkoenig, Vinod Chandran, \\ Dafna D. Gladman, Oliver M. FitzGerald, Ana-Maria Orbai ${ }^{\mathbb{D}}$, and Lihi Eder
}

\begin{abstract}
Objective. Systemic inflammation ${ }^{\wedge}$ is assessed through measurement of acute-phase reactants such as $\mathrm{C}$-reactive protein $(\mathrm{CRP})$ and erythrocyte sedimentation rate (ESR). With few exceptions, most randomized controlled trials (RCT) have assessed acute-phase reactants (CRP and ESR) as part of the American College of Rheumatology (ACR) 20 response criteria. As part of the Group for Research and Assessment of Psoriasis and Psoriatic Arthritis (GRAPPA)-Outcome Measures in Rheumatology (OMERACT) working group, we performed a systematic review of the literature to assess the performance of inflammatory biomarkers in psoriatic arthritis (PsA).

Methods. A systematic search of PubMed and Embase was performed. The search included peer-reviewed articles and scientific meeting abstracts about RCT and longitudinal observational studies that assessed systemic inflammation using acute-phase reactants in PsA. Studies were assessed following the components of the OMERACT filter including construct validity, responsiveness, and predictive validity.

Results. There were 2764 articles retrieved, and 71 articles were included for this systematic review. Twenty-eight articles reported CRP and/or ESR separately, and the remaining articles reported CRP and/or ESR as part of the ACR response criteria. Studies assessing OMERACT responsiveness provided conflicting reports. Inflammatory biomarkers had construct validity for more active disease. Evidence suggests that an elevation of ESR predicts cardiovascular outcomes.

Conclusion. Data regarding assessment of systemic inflammation using acute-phase reactants (CRP and ESR) are limited. There is only weak evidence to support normalization of these biomarkers in predicting good clinical outcomes/remission criteria. The predictive value for cardiovascular outcomes was generally good. Further studies to assess systemic inflammation in PsA using acute-phase reactants and other laboratory biomarkers are needed. (First Release November 1 2018; J Rheumatol 2019;46:266-73; doi:10.3899/jrheum.180195)
\end{abstract}

Key Indexing Terms:

PSORIATIC ARTHRITIS INFLAMMATION OUTCOMES OUTCOME ASSESSMENT

From the Department of Rheumatology, St. Vincent's University Hospital, Dublin, Ireland; Division of Rheumatology, University of Toronto, Krembil Research Institute, Toronto Western Hospital, Toronto, Ontario, Canada; Department of Rheumatology and Immunology, Singapore General Hospital; Duke-NUS Medical School, Singapore; University Hospitals, Cleveland, Ohio, USA; Conway Institute for Biomolecular Research, University College Dublin, Dublin, Ireland; Johns Hopkins University School of Medicine, Division of Rheumatology, Baltimore, Maryland, USA; Women's College Research Institute, Women's College Hospital; Department of Medicine, University of Toronto, Toronto, Ontario, Canada.

M. Elmamoun, MBBS, MRCPI, Department of Rheumatology, St. Vincent's University Hospital, and Division of Rheumatology, University of Toronto, Krembil Research Institute, Toronto Western Hospital; Y.Y. Leung, $M B C h B, M D$, Department of Rheumatology and Immunology, Singapore General Hospital, and Duke-NUS Medical School; D. O'Sullivan, BE, Patient Research Partner, St. Vincent's University Hospital; I. Steinkoenig, BA, Patient Research Partner, University Hospitals; V. Chandran, MBBS, $M D, D M, P h D$, Division of Rheumatology, University of Toronto, Krembil Research Institute, Toronto Western Hospital; D.D. Gladman, MD, FRCPC, Division of Rheumatology, University of Toronto, Krembil Research Institute, Toronto Western Hospital; O.M. FitzGerald, MD, Department of Rheumatology, St. Vincent's University Hospital, and Conway Institute for Biomolecular Research, University College Dublin; A.M. Orbai, MD, MHS, Johns Hopkins University School of Medicine,
Division of Rheumatology; L. Eder, MD, PhD, Women's College Research Institute, Women's College Hospital, and Department of Medicine, University of Toronto.

Address correspondence to Dr. L. Eder, Women's College Research Institute, Women's College Hospital, 76 Grenville St., Toronto, Ontario M5S1B2, Canada.E-mail: lihi.eder@wchospital.ca

Accepted for publication August 3, 2018.

Psoriatic arthritis (PsA) is a chronic immune-mediated inflammatory arthritis ${ }^{1}$ that occurs in $14-30 \%$ of patients with psoriasis and can lead to significant joint damage and disability $2,3,4,5$. PsA is a multifaceted, heterogeneous disease that manifests with the following clinical domains: peripheral arthritis, axial disease, enthesitis, dactylitis, and skin and nail disease. Measuring disease activity accurately can be difficult in PsA, because of the heterogeneity of the clinical features of the disease. Longitudinal studies have consistently demonstrated increased cardiovascular (CV) risk and related metabolic abnormalities in patients with psoriatic 
disease $e^{6,7,8,9}$. Several studies found an association between the extent of inflammation (both joint inflammation and acute-phase reactants) and poor disease outcomes, including the development of joint damage, cardiometabolic outcomes, and mortality ${ }^{10-17}$.

An updated PsA Core Domain Set was endorsed at Outcome Measures in Rheumatology (OMERACT) 2016 and includes musculoskeletal disease activity, skin disease activity, fatigue, pain, patient's global assessment (PtGA), physical function, health-related quality of life, and systemic inflammation $^{18}$.

Systemic inflammation may be assessed through measurement of acute-phase reactants such as C-reactive protein (CRP) and erythrocyte sedimentation rate (ESR). With few exceptions, most randomized controlled trials (RCT) have assessed acute-phase reactants (CRP/ESR) as part of the American College of Rheumatology (ACR) 20 response criteria primary efficacy endpoints.

The purpose of this paper is to review and summarize the data available for assessment of systemic inflammation using CRP and ESR in PsA RCT, as well as longitudinal observational studies (LOS) and cross-sectional studies. This systematic review will inform selection and/or development of an outcome measurement instrument for the assessment of systemic inflammation in PsA clinical trials.

\section{MATERIALS AND METHODS}

The original search strategy, up to May 2015, has been previously described to identify PsA RCT and observational studies ${ }^{19}$. The search included 2 databases, PubMed and Embase, and had 2 parts: the term for the disease concept "Psoriatic Arthritis" combined with operator "AND" with the validated Cochrane RCT sensitivity filter for each database $\mathrm{e}^{20,21}$. The literature search was updated from June 2015 to September 2016 using the same methodology; hand searches representing recent interleukin (IL)-17 and IL-6 inhibitors were included from September 2016. We excluded pediatric studies (children age 0-18 yrs) and used the following limits: human studies, English language (Figure 1).

The screening of all titles and abstracts for potential inclusion was performed by 2 investigators (ME and LE). Selected publications were retrieved in full, and 2 reviewers (ME and LE) independently assessed them for eligibility. To be included in the systematic review, original studies in the English language needed to fulfill the following criteria: (1) human

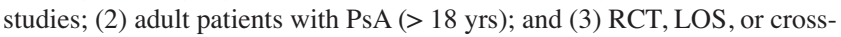
sectional studies. Exclusion criteria included animal studies, pediatrics (age 0-18), studies other than RCT, observational studies, and review articles.

Two authors (ME and YYL) independently extracted the data according to a standardized form. Discrepancies were resolved by consensus and involvement of a third author if needed (LE). For each study included, we recorded the following data: population, study design, study drug (if applicable), duration of study, sex, age (weighted mean), PsA disease duration (weighted mean), acute-phase reactant assessed separately, type of acute-phase reactant (ESR and/or CRP), and the extent of change of the acute-phase reactant.

The following components of the OMERACT filter ${ }^{22}$ were independently assessed for each study: responsiveness, construct validity, and predictive validity. Responsiveness was evaluated by the ability of the tool to demonstrate change in response to an intervention (e.g., study drug). Construct validity was achieved when the level of acute-phase reactants was concurrently compared with a theoretical concept of inflammation (e.g., clinical disease activity/disease state). Predictive validity was considered when acute-phase reactant predicted a theoretical concept related to systemic inflammation (e.g., clinical outcomes, radiographic joint damage, CV outcomes). We illustrated the process as recommended in the Preferred Reporting Items for the Systematic reviews and Meta-Analyses (PRISMA) statement ${ }^{23}$.

\section{RESULTS}

An initial literature search for PsA domains and instruments in PsA clinical trials ${ }^{19}$ retrieved 2079 entries, of which 60 full-text articles met inclusion criteria. We updated the search in PubMed and Embase and retrieved 685 additional entries. Eleven full-text articles were included, bringing the total number of full-text articles to 71, representing RCT, LOS, and cross-sectional studies (Figure 2).

Following review of full articles and supplementary data, only 28 articles were found to have reported ESR and/or CRP separately. The rest assessed CRP and/or ESR as part of ACR response without separate reporting of their results. The 28 articles represented 12 RCT [tumor necrosis factor inhibitor (2), methotrexate (1), IL-6 inhibitor (1), phosphodiesterase-4 inhibitor (3), IL-17 inhibitor (3), bisphosphonate (1), a panel of 57 protein biomarkers (1)] and 16 observational studies. The total number of patients with PsA included in the studies reviewed was $4761 ; 40 \%$ were female, their mean age was 48.2 years, and mean PsA duration was 8.2 years. The total number of patients in each study varied from 18 to 596 .

Eighteen articles assessed OMERACT responsiveness, the ability of CRP/ESR to demonstrate change in response to treatment (11 RCT, 7 observational). Nine studies ${ }^{24-32}$ have shown reduction of acute-phase reactants with different treatments. These studies have shown significant reduction of CRP/high-sensitivity CRP (hsCRP), and to a lesser extent, of ESR (Table 1).

Nine other studies ${ }^{33-41}$ did report a small change in CRP/ESR; however, they either did not report a $\mathrm{p}$ value or the $\mathrm{p}$ value was not significant (Table 1).

Ten studies (Table 2) have assessed OMERACT construct validity (level of biomarker correlated with disease state/disease activity measure) representing 3 RCT, 5 LOS, and 1 cross-sectional study. Acute-phase reactants were associated with clinical measures of disease activity. Shen, et $a l^{42}$ demonstrated that patients with PsA had higher CRP/ESR compared to controls, while Sterry, et $a l^{39}$ demonstrated that PsA patients with enthesitis had higher CRP than those without enthesitis.

The association between levels of inflammation at baseline and response to treatment has been assessed in 3 studies with conflicting results. Schett, et $a l^{32}$ reported that elevated CRP (CRP > $8 \mathrm{mg} / \mathrm{l})$ predicted ACR20 response to apremilast. In contrast, $\mathrm{Saad}$, et $a l^{43}$ reported that patients with high ESR (ESR $>28 \mathrm{~mm} / \mathrm{h})$ or CRP (CRP $>20 \mathrm{mg} / \mathrm{l})$ are less likely to achieve European League Against Rheumatism response (OR 0.54, 95\% CI 0.30-0.96) and remission (OR $0.54,95 \%$ CI 0.31-0.97) at 6 months. Further, Coates, et al ${ }^{44}$ demonstrated that low ESR predicted minimal disease activity (MDA) in multivariate model with RR 0.62 ( $\mathrm{p}<0.02)$.

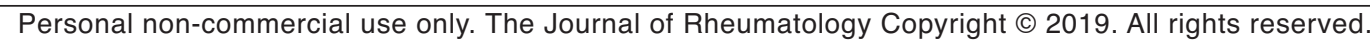




\section{Figure 1 - Search parameters and strategies of literature review}

Pubmed: ("Arthritis, Psoriatic"[Mesh] OR "Psoriatic arthritis" OR "psoriatic arthropathy" OR "arthritis psoriatica" OR "arthropathic psoriasis" OR "psoriasis arthropathica" OR "psoriatic arthropathy" OR "psoriatic polyarthritis" OR "psoriatic rheumatism") AND (randomized controlled trial [pt] OR controlled clinical trial [pt] OR "clinical trials as topic"[Mesh] OR randomized [tiab] OR placebo [tiab] OR drug therapy [sh] OR randomly [tiab] OR trial [tiab] OR groups [tiab]) NOT ("Animals"[MeSH] NOT ("Animals"[MeSH] AND "Humans"[MeSH])) NOT ("Child"[Mesh] OR "Infant"[Mesh] OR "Infant, Newborn"[MH] OR "Adolescent"[Mesh] OR "Child, Preschool"[MH] OR "child"[all] OR "infant"[all] OR "adolescent"[all] OR "children"[all] OR "infants"[all] OR "adolescents"[all] OR "pediatric patient"[all] OR "pediatric patients"[all] OR "adolescence"[all] OR "youth"[all] OR "youths"[all] OR "juvenile"[all] OR "childhood"[all] OR "teenager"[all] OR "teenagers"[all] OR "teen"[all] OR "teens"[all] OR "preschool child"[all] OR "neonate"[all] OR "newborn"[all] OR "baby"[all]) AND English[lang].

Embase: ('psoriatic arthritis'/exp OR "Psoriatic arthritis" OR "psoriatic arthropathy" OR "arthritis psoriatica" OR "arthropathic psoriasis" OR "psoriasis arthropathica" OR "psoriasis pustulosa arthropathica" OR "psoriatic arthropathy" OR "psoriatic polyarthritis" OR "psoriatic rheumatism") AND (random* OR factorial* OR crossover* OR cross NEXT/1 over* OR placebo* OR doubl* NEXT/1 blind* OR singl* NEXT/1 blind* OR assign* OR allocate* OR volunteer* OR 'crossover procedure'/exp OR 'double-blind procedure'/exp OR 'randomized controlled trials'/exp OR 'single-blind procedure'/exp) NOT ('animal'/exp NOT ('animal'/exp AND 'human'/exp)) NOT ('Child'/de OR 'Infant'/de OR 'Adolescent'/de OR 'preschool child'/exp OR 'child':ti,ab OR 'infant':ti,ab OR 'adolescent' OR 'children' OR 'infants' OR 'adolescents' OR 'pediatric patient' OR 'pediatric patients' OR 'adolescence' OR 'youth' OR 'youths' OR 'juvenile'/exp OR 'juvenile' OR 'childhood' OR 'teenager' OR 'teenagers' OR 'teen' OR 'teens' OR 'preschool child' OR 'neonate' OR 'newborn'/de OR 'newborn':ti,ab OR 'baby' OR 'babies' OR 'pediatric':ti,ab OR 'pediatrics':ti,ab OR 'paediatric':ti,ab OR 'paediatrics':ti,ab OR 'toddler'/exp OR 'toddler' OR 'toddlers') AND [english]

Figure 1. A list of the key words and strategies used to conduct the literature review.

One other study assessed other potential inflammatory biomarkers. Ademowo, et $a l^{45}$, using a proteomic approach in patients with PsA, identified a panel of 57 protein biomarkers in synovial tissue samples of patients with PsA prior to therapy that predicted treatment response to biologic therapy with an area under the curve of 0.76 . This novel biomarker panel was developed to be measured at baseline to predict patient response to biologics (adalimumab and abatacept). Some of these proteins on the candidate biomarker panel [fibrinogen, type 11 collagen, serum amyloid A, haptoglobin, and the S100 family proteins (A8, A9, A11, and A12)] have been found previously to play significant roles in inflammation ${ }^{45}$. This study suggests that novel biomarkers may be used in the future to predict PsA response to treatment.

Two $\operatorname{LOS}^{30,46}$ and a cross-sectional study ${ }^{47}$ reported that ESR and CRP do not predict MDA, 28-joint Disease Activity Score remission, PtGA, physician's global assessment, and Assessment of Spondyloarthritis international Society partial remission. No study has evaluated the value of ESR/CRP in predicting radiographic joint damage. Castaneda, et al ${ }^{48}$ assessed CV morbidity and associated risk factors for CV disease in Spanish patients with chronic inflammatory rheumatic diseases and unexposed individuals attending rheumatology clinics in a cross-sectional study. They did not establish a statistically significant association between inflammatory markers and CV risk in the PsA group (721 out of 2234 patients); however, most patients generally had mild disease activity at recruitment, were followed periodically by rheumatologists, and over $40 \%$ were treated with biologics. Most of the patients had low levels of disability and the acute-phase reactants were within normal range.

Regarding OMERACT predictive validity (predictive validity was considered when acute-phase reactant predicted radiographic damage or clinical outcome), 4 LOS evaluated the predictive validity of ESR and CRP (Table 3). Shen, et $a l^{42}$ demonstrated that cumulative ESR (defined as cumulative averages of ESR over time) was associated with increased arterial stiffness, assessed by pulse wave velocity, independently of traditional CV risk factors (OR 9.455, 95\% CI $1.939-46.093 ; \mathrm{p}=0.005)$. Eder, et al ${ }^{10,15}$ showed in 2 different studies that elevated levels of ESR were associated with increased CV risk. In the age- and sex-adjusted models, increased adjusted mean ESR (OR 1.41, 95\% CI 1.09-1.82) was associated with a more severe degree of carotid atherosclerotic plaques in patients with PsA. In addition, in a longitudinal cohort study of 1091 patients with PsA, Eder, et al ${ }^{10}$ demonstrated that ESR was an independent predictor of

Personal non-commercial use only. The Journal of Rheumatology Copyright (c) 2019. All rights reserved. 


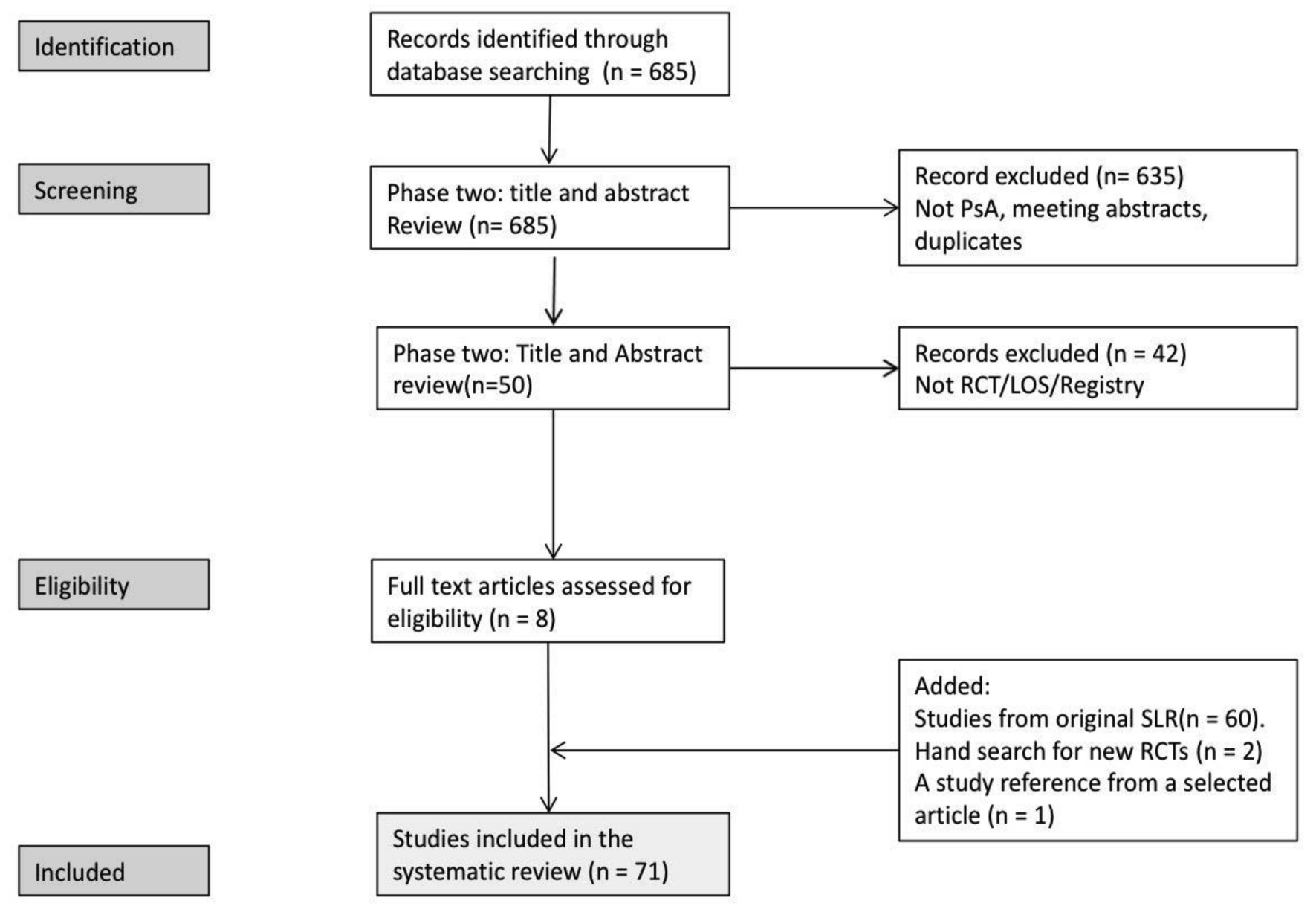

Figure 2. Preferred Reporting Items for Systematic Reviews and Meta-Analyses (PRISMA) flow diagram, record identification, screening, eligibility, and inclusion. PsA: psoriatic arthritis; RCT: randomized controlled trial; LOS: longitudinal observational studies; SLR: systematic literature review.

clinical $\mathrm{CV}$ events in women after controlling for $\mathrm{CV}$ risk factors (RR 1.83, p = 0.02). Geijer, et $a l^{49}$ have reported in univariate analysis that baseline ESR correlated with baseline radiographic joint damage as assessed by Wassenberg scores $(\mathrm{p}=0.027)$.

\section{DISCUSSION}

Systemic inflammation characterizes psoriatic disease and the assessment of the extent of inflammation using laboratory biomarkers has a potential for improved evaluation of disease activity in patients with PsA. To our knowledge, this is the first study to assess systemic inflammation in PsA using the OMERACT filter. This systematic literature review represents a critical examination of the published data regarding the state of validation of the most commonly used inflammatory biomarkers in PsA.

In this systematic review, all studies have assessed an acute-phase reactant: CRP, hsCRP, or ESR. However, only $40 \%$ reported the results of these biomarkers separately, even though all RCT have assessed these biomarkers as part of the primary endpoint, the ACR20 response. Data available for evidence synthesis were therefore limited.

Studies assessing OMERACT responsiveness provided conflicting reports. Nine of these studies ${ }^{24-32}$ demonstrated responsiveness with treatment, while 9 other studies ${ }^{33-41}$ did not report significant results. Clearly there is a need for more homogeneous studies to assess this component further with larger RCT or novel biomarkers.

Inflammatory biomarkers had good construct validity, with CRP/ESR being higher in patients with PsA, and patients with enthesitis versus those without enthesitis ${ }^{39,42}$. While the association between ESR/CRP and clinical disease outcomes was conflicting, there was more evidence to suggest that an elevation of ESR predicts CV outcomes. CRP, which was associated with increased $\mathrm{CV}$ risk in chronic inflammatory arthritis ${ }^{50}$, was not associated with CV risks in PsA based on a single cross-sectional study. This finding may be explained by the relatively low levels of chronic inflammation found in PsA using only traditional methods (CRP, ESR).

$$
\text { Personal non-commercial use only. The Journal of Rheumatology Copyright @ } 2019 \text {. All rights reserved. }
$$


Table 1. Studies that assessed responsiveness of inflammatory markers to treatment.

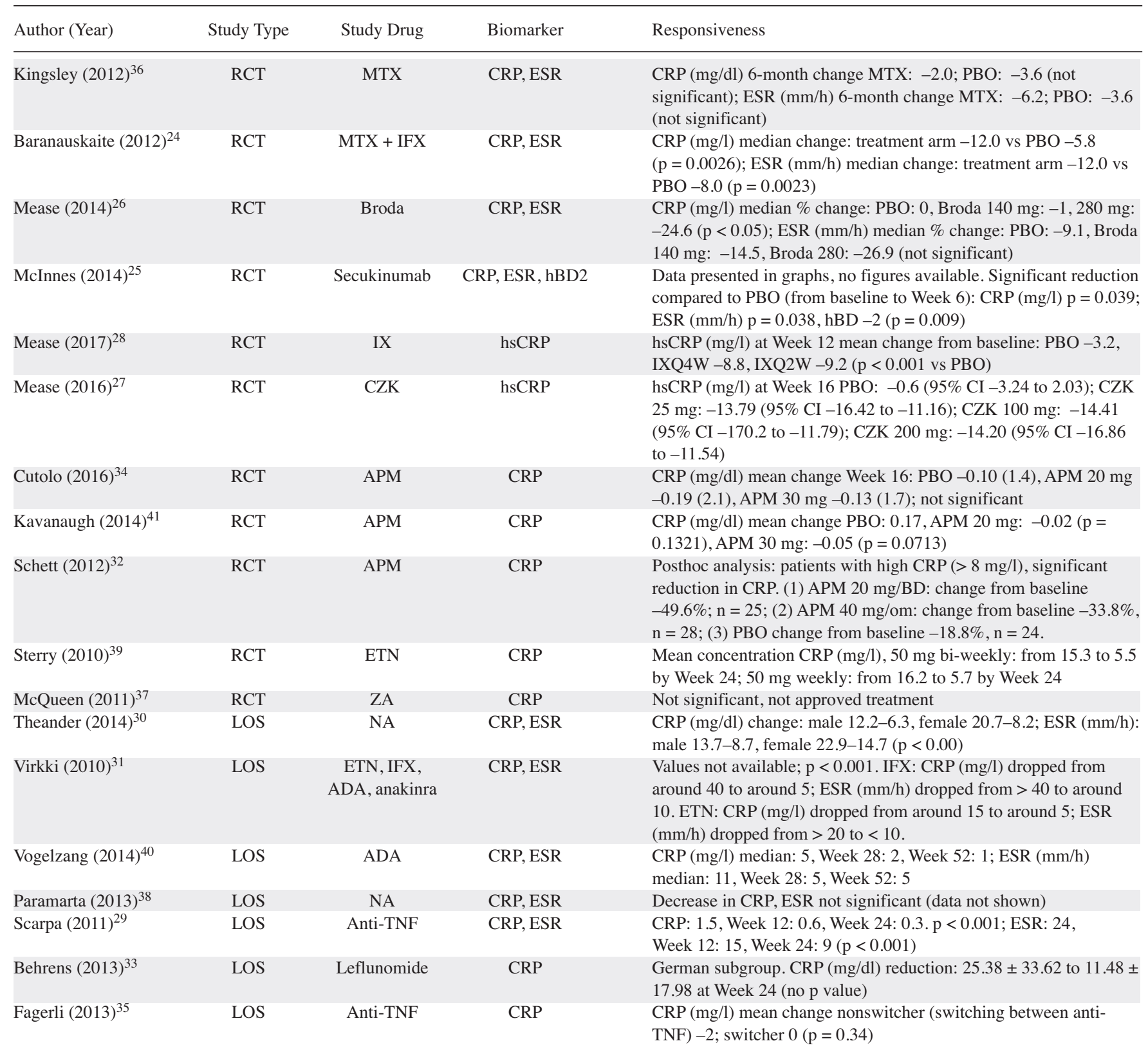

CRP: C-reactive protein; hsCRP: high-sensitivity CRP; ESR: erythrocyte sedimentation rate; hBD2: human $\beta$-defensin 2; RCT: randomized controlled trial; LOS: longitudinal observational study; PBO: placebo; MTX: methotrexate; IFX: infliximab; ETN: etanercept; ADA: adalimumab; APM: apremilast; CZK: clazakizumab; TNF: tumor necrosis factor; IX: ixekizumab; IXQ2W: IX every 2 weeks; IXQ4W: IX every 4 weeks; ZA: zalendronic acid; Broda: brodalumab; NA: not applicable; BD: twice daily; om: daily.

One of the limitations of our review is that not all papers reported the results of CRP/ESR separately and therefore only a few studies inform construct and predictive validity. Moreover, some of the studies were observational, raising the issue of selection bias and the uncertainty of the comparability of groups.

Inflammatory biomarkers have good construct validity based on their association with active disease. Inflammatory biomarkers have been incorporated into composite measures to assess clinical response in clinical trials. However, when used alone they provide inconsistent evidence of responsiveness in clinical trials. There is only weak evidence to support these biomarkers in predicting good clinical outcomes/remission criteria. Derived from 4 studies, the predictive value for $\mathrm{CV}$ outcomes was generally good.

Further large RCT to assess systemic inflammation in PsA using acute-phase reactants and high-sensitivity assays are needed. We recommend that all future RCT should assess and 
Table 2. Studies that assessed construct validity.

\begin{tabular}{|c|c|c|c|c|}
\hline Author (Year) & Study Type & Study Drug & Biomarker & OMERACT/Construct Validity \\
\hline Ademowo $(2016)^{45}$ & $\mathrm{RCT}$ & $\mathrm{ADA}$ & 57 protein biomarkers & Predict treatment response, AUC 0.76 \\
\hline Sterry $(2010)^{39}$ & RCT & ETN & CRP & $\begin{array}{l}\text { Patients with enthesitis had higher } \mathrm{CRP}(\mathrm{mg} / \mathrm{l}) \text { at baseline than those without } \\
\text { enthesitis. }\end{array}$ \\
\hline Schett $(2012)^{32}$ & RCT & APM & CRP & $\begin{array}{l}\text { A greater percentage of APM-treated patients with a baseline CRP level of }>8 \\
\text { mg/l achieved an ACR } 20 \text { response compared with patients whose baseline } \\
\text { CRP level was } \leq 8 \mathrm{mg} / \mathrm{l}(\mathrm{p} \leq 0.005) \text {. }\end{array}$ \\
\hline Iannone $(2013)^{46}$ & LOS & NA & ESR, CRP & $\begin{array}{l}\text { Baseline ESR and CRP }(\mathrm{mg} / \mathrm{dl}) \text { do not predict DAS28 remission: (OR } 1.03 \text {, } \\
\mathrm{p}=0.20) \text { and }(\mathrm{OR} 0.84, \mathrm{p}=0.33) \text {, respectively. }\end{array}$ \\
\hline Saad $(2010)^{43}$ & LOS & $\begin{array}{l}\text { Anti-TNF (ETN, } \\
\text { ADA, IFX) }\end{array}$ & ESR, CRP & $\begin{array}{l}\text { High CRP or ESR }(\mathrm{CRP}>20 \mathrm{mg} / 1 \text { or ESR }>28 \mathrm{~mm} / \mathrm{h}) \text { are less likely to } \\
\left.\text { achieve high EULAR response (OR } 0.54^{*}, 95 \% \text { CI } 0.30-0.96\right) \text { and remission } \\
\left(\text { OR } 0.54^{*}, 95 \% \text { CI } 0.31-0.97\right) \text { at } 6 \text { months. }\end{array}$ \\
\hline Shen $(2015)^{42}$ & LOS & NA & ESR, CRP & $\begin{array}{l}\text { PsA patients had higher ESR }(\mathrm{mm} / \mathrm{h}) \text { and CRP }(\mathrm{mg} / \mathrm{dl}) \text { compared to healthy } \\
\text { controls. }\end{array}$ \\
\hline Castaneda $(2015)^{48}$ & Cross-sectional & NA & ESR, CRP & $\begin{array}{l}\text { CRP (mg/l): PsA/CVE: } 3.6(\mathrm{IQR} 1.5-8.5) \text {, PsA no CVE } 2.9(1.3-6.0), \\
\mathrm{p}=0.334 . \text { ESR: PsA/CVE: } 10(7-30.2) \text {, PsA no CVE } 12(6-20.5), \mathrm{p}=0.491\end{array}$ \\
\hline
\end{tabular}

OMERACT: Outcome Measures in Rheumatology; CRP: C-reactive protein; ESR: erythrocyte sedimentation rate (mm/h); PsA: psoriatic arthritis; RCT: randomized controlled trial; LOS: longitudinal observational study; ADA: adalimumab; ETN: etanercept; APM: apremilast; AUC: area under the curve; TNF: tumor necrosis factor; SMD: standard mean difference; DAS28: 28-joint count Disease Activity Score; ACR: American College of Rheumatology; EULAR: European League Against Rheumatism; ASAS: Assessment of Spondyloarthritis international Society; MDA: minimal disease activity; CVE: cardiovascular event; IQR: interquartile range; NA: not applicable; RR: rate ratio; IFX: infliximab.

Table 3. Studies that assessed predictive validity of inflammatory biomarkers.

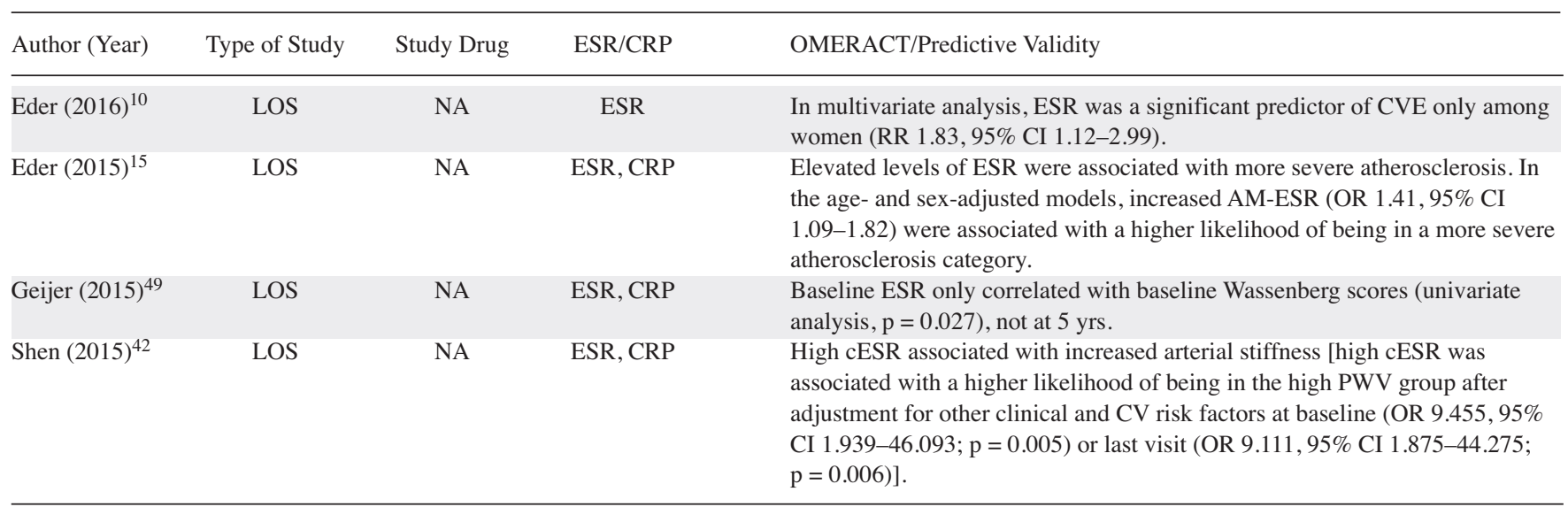

CRP: C-reactive protein (mg/dl); ESR: erythrocyte sedimentation rate (mm/h); cESR: cumulative ESR; OMERACT: Outcome Measures in Rheumatology; LOS: longitudinal observational study; CV: cardiovascular; CVE: CV event; PWV: pulse wave velocity; AM: adjusted mean; NA: not applicable.

report the results of acute-phase reactants/systemic inflammation separately. Additional studies are also needed to identify novel laboratory biomarkers for the assessment of systemic inflammation in PsA.

\section{REFERENCES}

1. Ritchlin CT, Colbert RA, Gladman DD. Psoriatic arthritis. N Engl J Med 2017;376:2095-6.
2. Gladman DD, Antoni C, Mease P, Clegg DO, Nash P. Psoriatic arthritis: epidemiology, clinical features, course, and outcome. Ann Rheum Dis 2005;64 Suppl 2:ii14-7.

3. Ibrahim G, Waxman R, Helliwell PS. The prevalence of psoriatic arthritis in people with psoriasis. Arthritis Rheumatol 2009; 61:1373-8.

4. Eder L, Gladman DD. Predictors for clinical outcome in psoriatic arthritis - what have we learned from cohort studies? Expert Rev Clin Immunol 2014;10:763-70. 
5. Gladman DD. Clinical features and diagnostic considerations in psoriatic arthritis. Rheum Dis Clin North Am 2015;41:569-79.

6. Gladman DD, Ang M, Su L, Tom BD, Schentag CT, Farewell VT. Cardiovascular morbidity in psoriatic arthritis. Ann Rheum Dis 2009;68:1131-5

7. Han C, Robinson DW Jr, Hackett MV, Paramore LC, Fraeman KH, Bala MV. Cardiovascular disease and risk factors in patients with rheumatoid arthritis, psoriatic arthritis, and ankylosing spondylitis. J Rheumatol 2006;33:2167-72.

8. Ogdie A, Yu Y, Haynes K, Love TJ, Maliha S, Jiang Y, et al. Risk of major cardiovascular events in patients with psoriatic arthritis, psoriasis and rheumatoid arthritis: a population-based cohort study. Ann Rheum Dis 2015;74:326-32.

9. Polachek A, Touma Z, Anderson M, Eder L. Risk of cardiovascular morbidity in patients with psoriatic arthritis: a meta-analysis of observational studies. Arthritis Care Res 2017;69:67-74.

10. Eder L, Wu Y, Chandran V, Cook R, Gladman DD. Incidence and predictors for cardiovascular events in patients with psoriatic arthritis. Ann Rheum Dis 2016;75:1680-6.

11. Gonzalez-Juanatey C, Llorca J, Amigo-Diaz E, Dierssen T, Martin J, Gonzalez-Gay MA. High prevalence of subclinical atherosclerosis in psoriatic arthritis patients without clinically evident cardiovascular disease or classic atherosclerosis risk factors. Arthritis Rheumatol 2007;57:1074-80.

12. Gonzalez-Juanatey C, Llorca J, Miranda-Filloy JA, Amigo-Diaz E, Testa A, Garcia-Porrua C, et al. Endothelial dysfunction in psoriatic arthritis patients without clinically evident cardiovascular disease or classic atherosclerosis risk factors. Arthritis Rheumatol 2007;57:287-93.

13. Eder L, Zisman D, Barzilai M, Laor A, Rahat M, Rozenbaum M, et al. Subclinical atherosclerosis in psoriatic arthritis: a case-control study. J Rheumatol 2008;35:877-82.

14. Bond SJ, Farewell VT, Schentag CT, Gladman DD. Predictors for radiological damage in psoriatic arthritis: results from a single centre. Ann Rheum Dis 2007;66:370-6.

15. Eder L, Thavaneswaran A, Chandran V, Cook R, Gladman DD. Increased burden of inflammation over time is associated with the extent of atherosclerotic plaques in patients with psoriatic arthritis. Ann Rheum Dis 2015;74:1830-5.

16. Eder L, Chandran V, Cook R, Gladman DD. The risk of developing diabetes mellitus in patients with psoriatic arthritis: a cohort study. J Rheumatol 2017;44:286-91.

17. Gladman DD. Mortality in psoriatic arthritis. Clin Exp Rheumatol 2008;5 Suppl 51:S62-5.

18. Orbai AM, de Wit M, Mease PJ, Callis Duffin K, Elmamoun M, Tillett W, et al. Updating the psoriatic arthritis (PsA) core domain set: a report from the PsA Workshop at OMERACT 2016. J Rheumatol 2017; 44:1522-8.

19. Kalyoncu U, Ogdie A, Campbell W, Bingham CO 3rd, de Wit M, Gladman DD, et al. Systematic literature review of domains assessed in psoriatic arthritis to inform the update of the psoriatic arthritis core domain set. RMD Open 2016;2:e000217.

20. Glanville JM, Lefebvre C, Miles JN, Camosso-Stefinovic J. How to identify randomized controlled trials in MEDLINE: ten years on. J Med Libr Assoc 2006;94:130-6.

21. Lefebvre C, Eisinga A, McDonald S, Paul N. Enhancing access to reports of randomized trials published world-wide - the contribution of EMBASE records to the Cochrane Central Register of Controlled Trials (CENTRAL) in The Cochrane Library. Emerg Themes Epidemiol 2008;5:13.

22. Boers M, Kirwan JR, Tugwell P, Beaton D, Bigham CO III, Conaghan PG, et al. The OMERACT Handbook. 2017. [Internet. Accessed October 18, 2018.] Available from: https://omeract.org/resources

23. Moher D, Liberati A, Tetzlaff J, Altman DG; PRISMA Group.
Preferred reporting items for systematic reviews and meta-analyses: the PRISMA statement. J Clin Epidemiol 2009;62:1006-12.

24. Baranauskaite A, Raffayova H, Kungurov NV, Kubanova A, Venalis A, Helmle L, et al; RESPOND investigators. Infliximab plus methotrexate is superior to methotrexate alone in the treatment of psoriatic arthritis in methotrexate-naive patients: the RESPOND study. Ann Rheum Dis 2012;71:541-8.

25. McInnes IB, Sieper J, Braun J, Emery P, van der Heijde D, Isaacs JD, et al. Efficacy and safety of secukinumab, a fully human anti-interleukin-17A monoclonal antibody, in patients with moderate-to-severe psoriatic arthritis: a 24-week, randomised, double-blind, placebo-controlled, phase II proof-of-concept trial. Ann Rheum Dis 2014;73:349-56.

26. Mease PJ, Genovese MC, Greenwald MW, Ritchlin CT, Beaulieu AD, Deodhar A, et al. Brodalumab, an anti-IL17RA monoclonal antibody, in psoriatic arthritis. N Engl J Med 2014;370:2295-306.

27. Mease PJ, Gottlieb AB, Berman A, Drescher E, Xing J, Wong R, et al. The efficacy and safety of clazakizumab, an anti-interleukin-6 monoclonal antibody, in a phase IIb study of adults with active psoriatic arthritis. Arthritis Rheumatol 2016;68:2163-73.

28. Mease PJ, van der Heijde D, Ritchlin CT, Okada M, Cuchacovich RS, Shuler CL, et al. Ixekizumab, an interleukin-17A specific monoclonal antibody, for the treatment of biologic-naive patients with active psoriatic arthritis: results from the 24-week randomised, double-blind, placebo-controlled and active (adalimumab)-controlled period of the phase III trial SPIRIT-P1. Ann Rheum Dis 2017;76:79-87.

29. Scarpa R, Atteno M, Lubrano E, Provenzano G, D'Angelo S, Spadaro A, et al. The effectiveness and safety of TNF-alpha blockers in the treatment of early psoriatic arthritis: an Italian multicentre longitudinal observational pilot study. Clin Rheumatol 2011;30:1063-7.

30. Theander E, Husmark T, Alenius GM, Larsson PT, Teleman A, Geijer M, et al. Early psoriatic arthritis: short symptom duration, male gender and preserved physical functioning at presentation predict favourable outcome at 5-year follow-up. Results from the Swedish Early Psoriatic Arthritis Register (SwePsA). Ann Rheum Dis 2014;73:407-13.

31. Virkki LM, Sumathikutty BC, Aarnio M, Valleala H, Heikkila R, Kauppi M, et al. Biological therapy for psoriatic arthritis in clinical practice: outcomes up to 2 years. J Rheumatol 2010;37:2362-8.

32. Schett G, Wollenhaupt J, Papp K, Joos R, Rodrigues JF, Vessey AR, et al. Oral apremilast in the treatment of active psoriatic arthritis: results of a multicenter, randomized, double-blind, placebo-controlled study. Arthritis Rheumatol 2012;64:3156-67.

33. Behrens F, Finkenwirth C, Pavelka K, Stolfa J, Sipek-Dolnicar A, Thaci D, et al. Leflunomide in psoriatic arthritis: results from a large European prospective observational study. Arthritis Care Res 2013;65:464-70

34. Cutolo M, Myerson GE, Fleischmann RM, Liote F, Diaz-Gonzalez F, Van den Bosch F, et al. A phase III, randomized, controlled trial of apremilast in patients with psoriatic arthritis: results of the PALACE 2 trial. J Rheumatol 2016;43:1724-34.

35. Fagerli KM, Lie E, van der Heijde D, Heiberg MS, Kalstad S, Rodevand E, et al. Switching between TNF inhibitors in psoriatic arthritis: data from the NOR-DMARD study. Ann Rheum Dis 2013;72:1840-4.

36. Kingsley GH, Kowalczyk A, Taylor H, Ibrahim F, Packham JC, McHugh NJ, et al. A randomized placebo-controlled trial of methotrexate in psoriatic arthritis. Rheumatology 2012;51:1368-77.

37. McQueen F, Lloyd R, Doyle A, Robinson E, Lobo M, Exeter M, et al. Zoledronic acid does not reduce MRI erosive progression in PsA but may suppress bone oedema: the Zoledronic Acid in Psoriatic Arthritis (ZAPA) Study. Ann Rheum Dis 2011;70:1091-4.

38. Paramarta JE, De Rycke L, Ambarus CA, Tak PP, Baeten D. 
Undifferentiated spondyloarthritis vs ankylosing spondylitis and psoriatic arthritis: a real-life prospective cohort study of clinical presentation and response to treatment. Rheumatology 2013;52:1873-8

39. Sterry W, Ortonne JP, Kirkham B, Brocq O, Robertson D, Pedersen $\mathrm{RD}$, et al. Comparison of two etanercept regimens for treatment of psoriasis and psoriatic arthritis: PRESTA randomised double blind multicentre trial. BMJ 2010;340:c147.

40. Vogelzang EH, Kneepkens EL, Nurmohamed MT, van Kuijk AW, Rispens T, Wolbink G, et al. Anti-adalimumab antibodies and adalimumab concentrations in psoriatic arthritis; an association with disease activity at 28 and 52 weeks of follow-up. Ann Rheum Dis 2014;73:2178-82.

41. Kavanaugh A, Mease PJ, Gomez-Reino JJ, Adebajo AO,

Wollenhaupt J, Gladman DD, et al. Treatment of psoriatic arthritis in a phase 3 randomised, placebo-controlled trial with apremilast, an oral phosphodiesterase 4 inhibitor. Ann Rheum Dis 2014;73:1020-6.

42. Shen J, Shang Q, Li EK, Leung YY, Kun EW, Kwok LW, et al. Cumulative inflammatory burden is independently associated with increased arterial stiffness in patients with psoriatic arthritis: a prospective study. Arthritis Res Ther 2015;17:75.

43. Saad AA, Ashcroft DM, Watson KD, Symmons DP, Noyce PR, Hyrich KL, et al; BSRBR. Efficacy and safety of anti-TNF therapies in psoriatic arthritis: an observational study from the British Society for Rheumatology Biologics Register. Rheumatology 2010; 49:697-705

44. Coates LC, Cook R, Lee KA, Chandran V, Gladman DD. Frequency, predictors, and prognosis of sustained minimal disease activity in an observational psoriatic arthritis cohort. Arthritis Care Res 2010;62:970-6.
45. Ademowo OS, Hernandez B, Collins E, Rooney C, Fearon U, van Kuijk AW, et al. Discovery and confirmation of a protein biomarker panel with potential to predict response to biological therapy in psoriatic arthritis. Ann Rheum Dis 2016;75:234-41.

46. Iannone F, Fanizzi R, Scioscia C, Anelli MG, Lapadula G. Body mass does not affect the remission of psoriatic arthritis patients on anti-TNF- $\alpha$ therapy. Scand J Rheumatol 2013;42:41-4.

47. Kılıç G, Kılıç E, Nas K, Karkucak M, Çapkın E, Dağlı AZ, et al. Comparison of ASDAS and BASDAI as a measure of disease activity in axial psoriatic arthritis. Clin Rheumatol 2015;34:515-21.

48. Castaneda S, Martin-Martinez MA, Gonzalez-Juanatey C, Llorca J, Garcia-Yebenes MJ, Perez-Vicente S, et al; CARMA Project Collaborative Group. Cardiovascular morbidity and associated risk factors in Spanish patients with chronic inflammatory rheumatic diseases attending rheumatology clinics: baseline data of the CARMA Project. Semin Arthritis Rheum 2015;44:618-26.

49. Geijer M, Lindqvist U, Husmark T, Alenius GM, Larsson PT, Teleman A, et al. The Swedish Early Psoriatic Arthritis Registry 5-year followup: substantial radiographic progression mainly in men with high disease activity and development of dactylitis. J Rheumatol 2015;42:2110-7.

50. Zegkos T, Kitas G, Dimitroulas T. Cardiovascular risk in rheumatoid arthritis: assessment, management and next steps. Ther Adv Musculoskelet Dis 2016;8:86-101. 